\title{
Outcomes of people with psychotic disorders in a community-based rehabilitation programme in rural India
}

\author{
Sudipto Chatterjee, Aravind Pillai, Sumeet Jain, Alex Cohen and Vikram Patel
}

\section{Background}

There is little evidence of the feasibility, acceptability and impact of services for the care of people with psychotic disorders in low- and middle-income countries.

\section{Aims}

To describe the scaling up and impact of a community-based rehabilitation programme for people with psychotic disorders in a very-low-resource setting.

\section{Methods}

Longitudinal study of people with psychotic disorders who had been ill for an average of 8 years in a rural Indian community. All individuals received a community-based intervention package comprising psychotropic medications, psychoeducation, adherence management, psychosocial rehabilitation and support for livelihoods. The primary outcome was change in disability scores.

\section{Results}

The cohort consisted of 256 people with psychotic disorders (schizophrenia, bipolar affective disorder and other psychosis) of whom 236 people completed the end-point assessments (92\%), with a median follow-up of 46 months.
There were significant reductions $(P<0.05)$ in the levels of disability for the cohort, the vast majority (83.5\%) of whom engaged with the programme. On multivariate analyses, lower baseline disability scores, family engagement with the programme, medication adherence and being a member of a self-help group were independent determinants of good outcomes. Lack of formal education, a diagnosis of schizophrenia and dropping out of the programme were independent determinants of poor outcomes.

\section{Conclusions}

community-based rehabilitation is a feasible and acceptable intervention with a beneficial impact on disability for the majority of people with psychotic disorders in low-resource settings. The impact on disability is influenced by a combination of clinical, programme and social determinants.

\section{Declaration of interest}

S.C. and V.P. are associated with a randomised controlled trial evaluation of the community-based rehabilitation intervention described in this paper, funded by the Wellcome Trust.
Although repeated calls have been made for accessible, equitable, acceptable and effective services for people with severe mental disorders, ${ }^{1}$ a persistent and unacceptably large treatment gap remains for these conditions in low- and middle-income countries. ${ }^{2}$ Even though evidence-based packages of care for these disorders have been identified, ${ }^{3}$ the actual delivery of treatments in resource-constrained settings remains a challenge ${ }^{4}$ and is a global mental health priority. ${ }^{5}$ One of the most important barriers to appropriate service provision to people with persistent psychotic disorders is the lack of adequately trained specialist mental health personnel. ${ }^{6}$ Non-specialist, low-cost human resources are essential to implement public health-oriented services in lowand middle-income countries where specialist resource constraints are likely to continue. ${ }^{7}$ One such method is community-based rehabilitation where services are provided in close collaboration between specialists and locally available personnel, within an explicit human rights and developmental framework. ${ }^{8}$ We have previously reported on the efficacy of community-based rehabilitation for people with chronic schizophrenia in a rural area of India compared with routine out-patient care. ${ }^{9}$ Although community-based rehabilitation approaches are being more widely implemented in low- and middle-income countries, ${ }^{10}$ their acceptability, impact on social outcomes of service users, and determinants of these outcomes are inadequately described.

We describe the uptake and impact of a service using the community-based rehabilitation framework for people with psychotic disorders within a defined catchment area in a rural, impoverished community in India. The programme was implemented by the Ashagram Trust, a community-based nongovernmental organisation. We describe the functional (disability) outcomes of people with psychotic disorders; identify the determinants of their outcomes; and highlight the research and policy implications of this study for service provision in rural areas of low- and middle-income countries.

\section{Method}

\section{Setting}

The community-based rehabilitation programme was implemented in the administrative 'block' (subdistrict) of Pati, which is located in the district of Barwani in the state of Madhya Pradesh, India. Pati has a population of 125463 living in 106 villages, as per the 2001 census (www.censusindia.gov.in). The majority (92.6\%) of the people are 'scheduled tribes' (official government terminology for the indigenous people of India) who are dependent on seasonal agriculture and animal husbandry. Pati is one of the most underdeveloped areas in India with $82.6 \%$ living below the poverty line (defined as the cost of an average Indian food consumption basket amounting to 2400 calories/day for rural areas; this translates approximately into $\$ 2 \mathrm{USD} /$ day at current monetary rates). Prior to the rehabilitation programme, there were no mental health services in Pati.

\section{Sample}

Our previous rehabilitation programme ${ }^{9}$ was the template for the scaled up services in Pati. Services were provided to people with a 
broad range of mental disorders, viz. psychotic and common mental (depression and anxiety) disorders, epilepsy and intellectual disability. In this paper, we describe the outcomes of people with psychotic disorders - schizophrenia, bipolar disorders and 'other' psychotic disorders - who had experienced at least 6 months of the illness and had been enrolled in the programme for a minimum of 12 months, over a total median period of 46 months.

\section{The intervention}

To improve access to the population living in isolated locations, the community teams were based in four different 'clusters'. Each cluster consisted of four to five community-based rehabilitation workers supervised by a cluster coordinator. The rehabilitation workers received an initial 4-week training programme comprising modules covering the recognition and management of people with mental disorders (details of the training programme are available from S.C.). A continuing supervision process during the weekly meetings with the cluster coordinators, during monthly team meetings with the programme psychiatrist and during the psychiatrist's visit to the outreach camps was followed to improve and sustain the skills of these rehabilitation workers during the programme. The overall structure, personnel and their key roles in the programme are shown in online Fig. DS1.

Specialist care was provided by a psychiatrist through monthly outreach camps in each of the clusters. Usually arranged in a primary health clinic, these camps were held on a predesignated day of the month known to service users. In these camps, both new referrals and those being followed up were assessed, and drug treatments prescribed. Second-generation oral antipsychotic medication (risperidone and olanzapine) was the preferred choice since there are no significant cost differences between these and the first-generation antipsychotic medications in India. Selective serotonin reuptake inhibitors (fluoxetine and sertraline) were the most commonly used antidepressants, and mood stabilisers (lithium and carbamazepine) were used as necessary. Whenever clinically appropriate, depot antipsychotics (zuclopenthixol decanoate) and benzodiazepines (e.g. clonazepam, lorazepam) were also utilised. The individual components of the programme are described in online Table DS1. Self-help groups, comprising service users and community members, focused on livelihood support through microcredit facilities and social reintegration.

\section{Data collection}

Enrolment of participants in the community-based rehabilitation programme was initiated in September 2001 and the end-point assessment was conducted between May and August 2006. Data for each participant were collected at the point of programme entry and at the time of the end-point assessment. Verbal consent (in view of the very low literacy rates in the area) from both the participant and key family members was obtained routinely before the end-point data collection.

\section{Primary outcome}

The primary outcome was the change in disability scores between entry into the programme and at end-point. This was assessed using the Indian Disability Evaluation Assessment Scale (IDEAS). ${ }^{11}$ The IDEAS, which is scored after a semi-structured interview with the primary caregiver, measures disabilities in four domains: self-care, interpersonal activities, communication and understanding, and work. The global score generates four categories of disabilities (from none to severe).

\section{Process indicators}

Adherence to medication was coded as either complete, intermittent (total duration of non-adherence $<90$ days in a year) or non-adherent ( $\geqslant 90$ days in a year of not taking medication). These categories were generated from the tertiles of the distribution of adherence data. For analysis, those with complete and intermittent adherence were combined into one category of adherence. Adherence was recorded by programme staff during home visits; since all participants were living with families who were intimately involved in their treatment, ratings were made in consultation with caregivers to provide reliable information. Participants who did not adhere to medication were asked to identify the most important reason for not continuing with treatment; the three most common responses were lack of money, preventing them from accessing the monthly camps to pick up medications; lack of information about the camps; and medication-related problems (lack of improvement, or sideeffects). Each of these was rated as a dichotomous variable. Participants were rated as having dropped out of the programme when they did not engage with the programme and refused further services; all other participants (including those who had been discharged in a planned manner) were considered to be engaged with the programme. Participants were considered as members of the self-help groups if they had formally enrolled themselves and had attended at least two of the previous 6 monthly meetings. These data were extracted from the clinical records and verified by the respective cluster coordinator.

\section{Other baseline measures}

At the time of the initial assessment, the psychiatrist recorded participants' diagnoses using ICD-10 criteria $^{12}$ - the category of 'other psychoses' included those with schizoaffective disorder, delusional disorder, substance-induced chronic psychotic disorders and psychosis not otherwise specified. Duration of illness and other historical information were elicited from family care providers. All families were specifically asked whether lack of money to access treatment or treatment discontinuation was a reason why their family member had remained ill prior to engagement with the programme. During this initial engagement, the cluster coordinator made a global rating of the support provided to the participant by their family based on:

- whether the person was being helped to complete activities of daily living

- whether the person was encouraged to have some interactions within the family

- whether the family had made any effort to provide treatment in the previous 12 months

- whether the family were using any physical restraints on a regular basis.

If families did not provide any meaningful help despite having people in the house to do so, did not encourage interactions, had made no attempt to seek treatment (traditional healing or medical care) in the previous 12 months or were using physical restraints, they were rated as providing poor family support. The rehabilitation workers also collected sociodemographic and economic data from participants and their family using a modified version of a questionnaire that has been used in rural India (available from the authors on request).

\section{Other end-point measures}

To generate locally relevant measures of social outcomes for endpoint assessment, we conducted focus group discussions with the 
community team, service users and selected self-help group members to identify a list of social activities that the community usually participated in. From this initial list, we compiled the most commonly cited items, such as attending festivals, marriages or working regularly, and rated them as dichotomous responses. We also generated a list of assets which families had acquired during the course of the intervention that could be reliably assessed; this included livestock, farming equipment, home appliances and home improvement activities. The list of gains in household assets was combined into a dichotomous composite variable, any asset gained after programme. At end-point, the rehabilitation workers recorded their global assessment of the quality of the family's engagement with the programme based on the quality of the therapeutic alliance, engagement in psychoeducation sessions, their partnership in implementing care plans, supervision of adherence, encouraging social interactions outside of the home environment, emotional support for the person with the illness and participating in local self-help group activities. Families were rated as supportive if they met at least three of these criteria.

\section{Analysis}

The primary outcome measure was the change in IDEAS scores between baseline and end-point. The changes in scores were converted into three categories: minimal improvement $(<20 \%$ change from baseline), moderate improvement (20-40\% change from baseline) and marked improvement $(\geqslant 41 \%$ change from baseline). These were determined $a$ priori based on previous clinical experience and analysis of disability data from our earlier work. ${ }^{9}$

For the analysis of the determinants of outcomes, we analysed three broad domains of interest: baseline sociodemographic variables, clinical variables recorded at the time of enrolment and process indicators. Analysis of covariance (ANCOVA) was used for estimating associations between independent variables and the primary outcome measure. The baseline IDEAS score was used as a covariate in the analysis which generated the regression coefficient $(\beta)$ derived from the ANCOVA. All analyses were $a$ priori adjusted for age and gender. A stepwise approach was then used to identify the determinants of outcomes. First, the univariate association of each domain of variables was estimated. In the second step, variables found to be associated at a level of significance of $P<0.05$ in the univariate analyses were included in domain-specific multivariate analyses. This identified the variables independently associated with the outcome within each of these domains. Finally, the significant variables from the domain-specific analyses were entered in a multivariate model to identify the variables that independently predicted outcomes for this cohort. Statistical analyses were performed using Stata version 9 for Windows. Missing values were not imputed.

\section{Results}

A total of 256 people with psychotic disorders were enrolled in the programme, for $236(92.2 \%)$ of whom we were able to complete end-point assessments. The median duration of follow-up was 46 months (range 12-52). Of the 20 people for whom end-point data were unavailable, 11 (4.3\%) had died, of whom 6 had died by suicide. Five people had migrated from the study area and four participants and their families refused to be interviewed for the end-point assessments.

\section{Sample characteristics}

Members of scheduled tribes comprised $86.9 \%$ of the cohort, and $84.7 \%$ of the families in the programme were living below the poverty line. Overall, $74.2 \%$ of the cohort were aged $20-45$ years, with males comprising $55 \%$ of the sample. Although $172(67 \%)$ participants were married, $25(9.7 \%)$ were separated as a result of the psychotic illness. In total, $78.5 \%$ of the cohort had not received any formal education, and 57\% were living in joint families. People with schizophrenia $(n=142,55.5 \%)$ constituted the largest proportion of the cohort; bipolar affective disorder was diagnosed in 71 people $(27.7 \%)$ and those with other psychoses constituted the remainder $(n=43,16.8 \%)$. On average, participants had been ill for 8 years and had a high level of disability (Table 1). Poverty was cited by over a third of participants $(36 \%)$ as the most important reason that limited access to treatment before enrolment in the rehabilitation programme. Overall, $31 \%$ of families were rated as not being supportive; poor family support was correlated with increasing duration of illness and a diagnosis of schizophrenia. At baseline, people with schizophrenia had relatively higher levels of disability and were significantly more likely to be separated from their spouses and families compared with other diagnostic groups (Table 1).

\section{Process indicators}

In the initial 2 years, approximately $80 \%$ of referrals to the programme were made by rehabilitation workers. In contrast, the self-help groups emerged as the single largest (80\%) source of referrals in the last 2 years of the programme (Fig. 1).

At end-point, $83.5 \%$ of the cohort was rated as being engaged with the programme. Among those who had dropped out but who completed end-point assessments $(n=39,16.5 \%)$, the most common reason $(78 \%)$ was the lack of family support. In total, 66 (28\%) participants were non-adherent with their recommended treatments; the most commonly cited reason (84\%) was the lack of money, which affected attendance at the outreach camps for clinical review.

At the time of the end-point assessment, there were 55 self-help groups with regular within-group microcredit activities; some of these had established linkages with banks and the local government to access funds for assistance with livelihood programmes such as horticulture and water conservation. Overall, 155 (65.7\%) participants were registered as members of these self-help groups.

\section{Prevalence of primary outcomes}

Marked improvement in IDEAS scores was reported for $50 \%$ (95\% CI $43.7-56.3 ; n=118)$ of participants, and $40 \%$ (95\% CI $34.2-46.6 ; n=95)$ showed moderate improvement. The remaining $10 \%$ (95\% CI 6.5-14.2; $n=23$ ) showed minimal improvement.

\section{Social outcomes and their association with end-point disability}

The social outcomes of the cohort, assessed at end-point, indicated that the majority of participants had been taking part in normative community activities such as attending marriages $(82.6 \%)$, participating in community festivals $(81.3 \%)$ and visiting relatives in another village (84.3\%). Most participants had also exercised their rights as citizens by attending the gram sabha or village development council meetings (64.7\%) and voting in village elections $(75.2 \%)$. The most common economic asset $(63 \%)$ gained by families during the course of the programme was additional livestock, followed by home appliances such as a bicycle (26\%); 68.2\% also secured employment in the National Rural Employment Guarantee (NREG) scheme. This assured the families of those living below the poverty line of employment, on stipulated minimum wages, for at least 100 days a year in local development work.

Bivariate analyses indicated that all of these social measures attending community festivals $(\beta=0.61, P<0.001)$; attending 


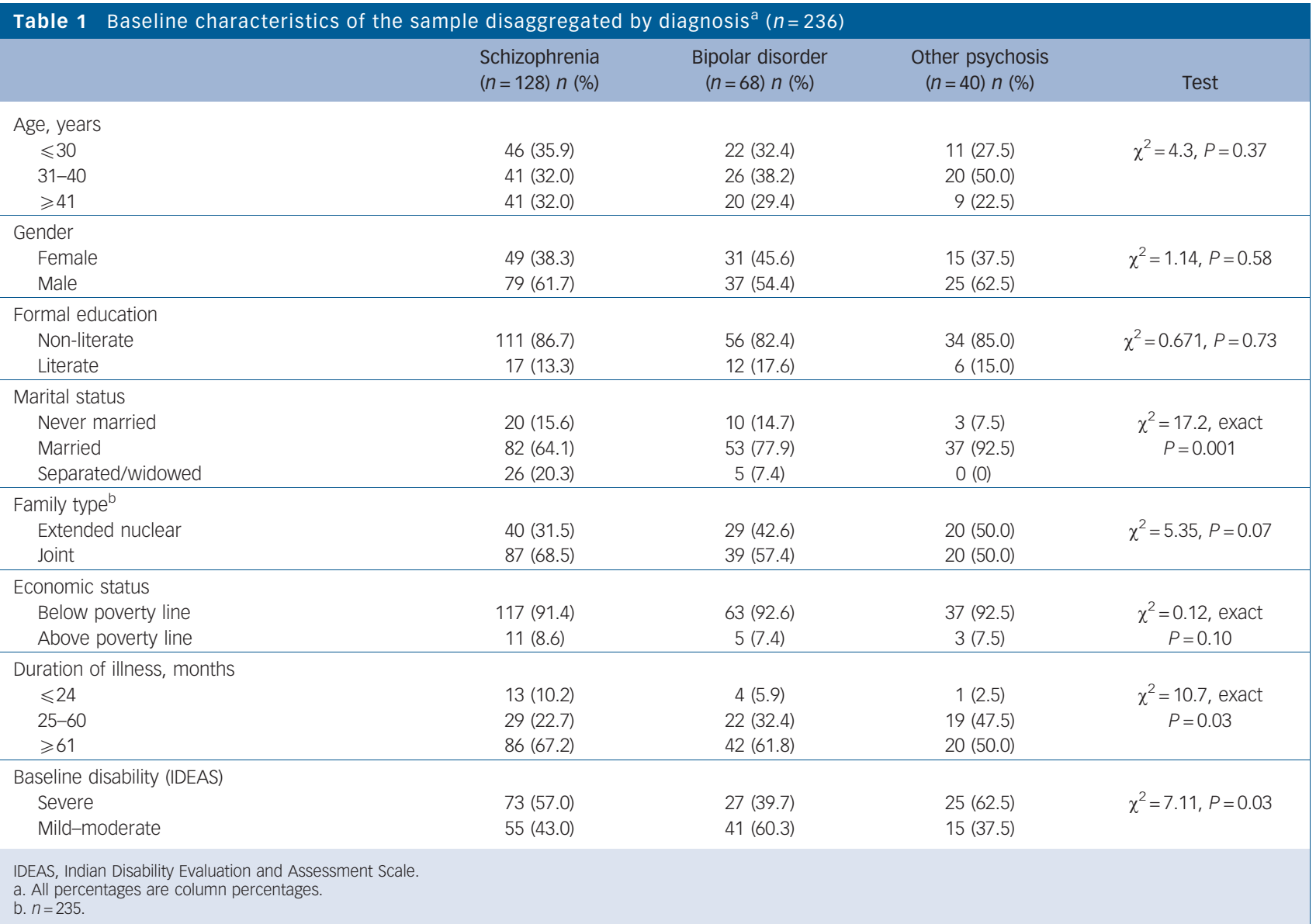

marriages $(\beta=0.82, \quad P<0.001)$; visiting relatives $(\beta=0.84$, $P<0.001)$; attending gram sabhas $(\beta=0.60, P<0.001)$; voting in local elections $(\beta=0.59, \quad P<0.001)$; acquiring new economic assets $(\beta=0.61, P<0.001)$; and access to the NREG $(\beta=0.67$, $P<0.001)$ - were closely correlated with the primary outcome. This confirms that the measures of disability and social functioning overlap significantly. These findings also suggest convergent validity of our primary outcome.

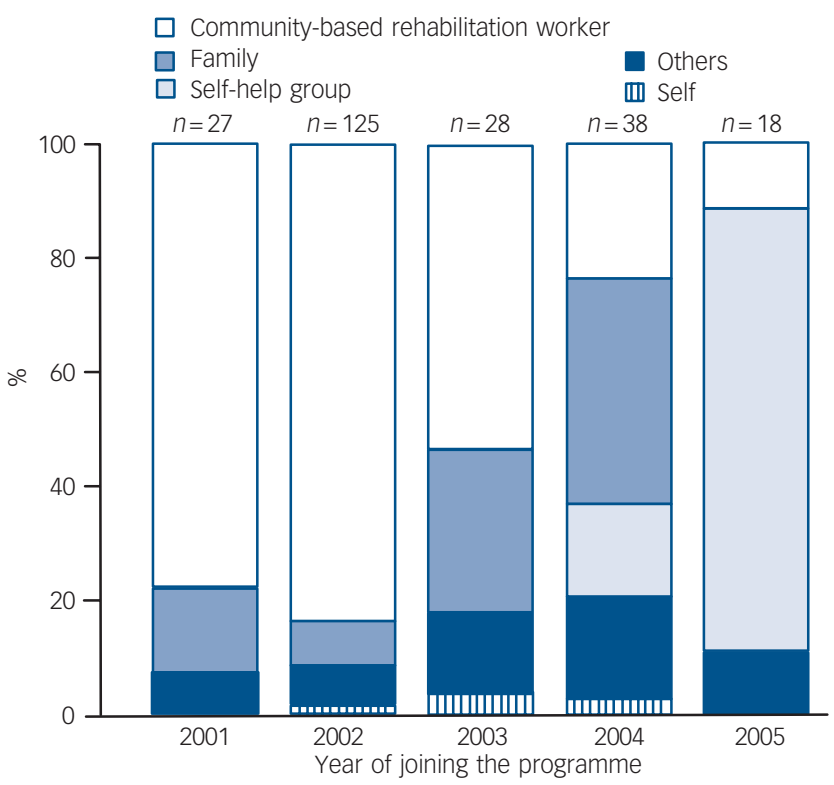

Fig. 1 Referral pattern of the community-based rehabilitation programme over time.

\section{Determinants of outcome}

Among the sociodemographic factors at entry, univariate analyses indicated that being married was associated with better outcome, whereas not having received any formal education, lack of family support and poverty limiting access to care before enrolment in the programme predicted a poorer outcome. Of the baseline clinical variables, the diagnosis of schizophrenia, an increasing duration of the illness and a higher baseline IDEAS score predicted poor outcomes (Table 2). On multivariate analysis, the diagnosis of schizophrenia, lack of formal education, lack of family support and being separated emerged as independent predictors of poor outcome.

The univariate analyses of the process indicators indicated that dropping out from the programme was associated with poor outcome, whereas medication adherence, active membership in self-help groups and families engaged with the programme were determinants of good outcomes (Table 3). Multivariate analysis of the process indicator domain showed that all these variables remained independently associated with outcome.

The final multivariate analysis identified lower baseline disability, adherence to prescribed medications, having a family engaged with the programme and being a member of a self-help groups as independent predictors of good outcomes. On the other hand, having a diagnosis of schizophrenia, not having any formal education and dropping out of the programme were independent predictors of poorer outcome.

\section{Outcomes and affective components of community- based rehabilitation}

Psychotic disorders pose a substantial burden of disability in lowand middle-income countries ${ }^{13}$ and providing effective, affordable 


\begin{tabular}{|c|c|c|c|c|c|}
\hline & \multicolumn{3}{|c|}{ Change in baseline IDEAS scores, $n(\%)$} & \multirow[b]{2}{*}{ Coefficient } & \multirow[b]{2}{*}{$P$} \\
\hline & $\begin{array}{c}<20 \%, \\
\text { no improvement }\end{array}$ & $\begin{array}{l}\text { 20-40\%, moderate } \\
\text { improvement }\end{array}$ & $\begin{array}{l}\geqslant 41 \%, \text { marked } \\
\text { improvement }\end{array}$ & & \\
\hline \multicolumn{6}{|l|}{ Gender } \\
\hline Female & $8(8.4)$ & $37(39.0)$ & $50(52.6)$ & 0.03 & 0.70 \\
\hline Male & $15(10.6)$ & $58(41.1)$ & $68(48.2)$ & ref. & - \\
\hline \multicolumn{6}{|l|}{ Age, years } \\
\hline$\leqslant 30$ & $6(7.6)$ & $34(43.0)$ & $39(49.4)$ & 0.04 & 0.72 \\
\hline $31-40$ & $12(13.8)$ & $29(33.3)$ & $46(52.9)$ & -0.03 & 0.74 \\
\hline$\geqslant 41$ & $5(7.1)$ & $32(45.7)$ & $33(47.1)$ & ref. & - \\
\hline \multicolumn{6}{|l|}{ Marital status } \\
\hline Un-married & $4(12.1)$ & $20(60.6)$ & $9(27.3)$ & 0.14 & 0.39 \\
\hline Married & $12(7.0)$ & $58(33.7)$ & $102(59.3)$ & 0.52 & $<0.001$ \\
\hline Separated/widowed & $7(22.6)$ & $17(54.8)$ & $7(22.6)$ & ref. & - \\
\hline \multicolumn{6}{|l|}{ Formal education } \\
\hline Non-literate & $23(11.4)$ & $85(42.3)$ & $93(46.3)$ & -0.40 & 0.001 \\
\hline Literate & 0 & $10(28.6)$ & 25 (71.4) & ref. & - \\
\hline \multicolumn{6}{|l|}{ ICD-10 diagnosis } \\
\hline Schizophrenia & $17(13.3)$ & $64(50.0)$ & $47(36.7)$ & -0.49 & $<0.001$ \\
\hline Bipolar disorder & $4(5.9)$ & $23(33.8)$ & $41(60.3)$ & -0.22 & 0.08 \\
\hline Other psychosis & $2(5.0)$ & $8(20.0)$ & $30(75.0)$ & ref. & - \\
\hline \multicolumn{6}{|c|}{ Duration of illness, months } \\
\hline$\leqslant 24$ & 0 & $11(61.1)$ & $7(38.9)$ & -0.02 & 0.91 \\
\hline $25-60$ & $5(7.1)$ & $24(34.3)$ & $41(58.6)$ & 0.13 & 0.17 \\
\hline$\geqslant 61$ & $18(12.2)$ & $60(40.5)$ & $70(47.3)$ & ref. & \\
\hline \multicolumn{6}{|c|}{ Poverty limiting access to treatment } \\
\hline Yes & $13(15.3)$ & $41(48.2)$ & $31(36.5)$ & -0.30 & $<0.001$ \\
\hline No & $10(6.6)$ & $54(35.8)$ & $87(57.6)$ & ref. & \\
\hline \multicolumn{6}{|l|}{ Family support } \\
\hline Poor & $14(18.9)$ & $37(50.0)$ & $23(31.1)$ & -0.39 & $<0.001$ \\
\hline Good & $9(5.6)$ & $58(35.8)$ & $95(58.6)$ & ref. & \\
\hline
\end{tabular}

\begin{tabular}{|c|c|c|c|c|c|}
\hline & \multicolumn{3}{|c|}{ Change in baseline IDEAS scores, $n$ (\%) } & \multirow[b]{2}{*}{ Coefficient } & \multirow[b]{2}{*}{$P$} \\
\hline & $\begin{array}{c}<20 \%, \\
\text { no improvement }\end{array}$ & $\begin{array}{l}20-40 \% \text {, moderate } \\
\text { improvement }\end{array}$ & $\begin{array}{l}>40 \% \text {, marked } \\
\text { improvement }\end{array}$ & & \\
\hline \multicolumn{6}{|l|}{ Duration of service contact, ${ }^{\mathrm{b}}$ years } \\
\hline$<2$ & $3(6.7)$ & $23(51.1)$ & $19(42.2)$ & -0.08 & 0.48 \\
\hline $2-3$ & $2(6.1)$ & $7(21.2)$ & $24(72.7)$ & 0.28 & 0.02 \\
\hline$\geqslant 3.1$ & $18(11.4)$ & $65(41.1)$ & $75(47.5)$ & ref. & \\
\hline \multicolumn{6}{|l|}{ Medication adherence ${ }^{\mathrm{b}}$} \\
\hline Yes & $2(1.2)$ & $61(36.1)$ & $106(62.7)$ & 0.77 & $<0.001$ \\
\hline No & $21(31.8)$ & $34(51.5)$ & $11(16.7)$ & ref. & \\
\hline \multicolumn{6}{|l|}{ Status of follow-up ${ }^{b}$} \\
\hline Dropped out & $18(46.2)$ & $19(48.6)$ & $2(2.7)$ & -0.95 & $<0.001$ \\
\hline Continued follow-up and planned discharge & $5(2.6)$ & $76(38.8)$ & $116(58.7)$ & ref. & \\
\hline \multicolumn{6}{|l|}{ Family engagement ${ }^{c}$} \\
\hline Present & $7(3.9)$ & $63(34.6)$ & $112(61.5)$ & 0.76 & $<0.001$ \\
\hline Absent & $16(29.6)$ & $32(59.3)$ & $6(11.1)$ & ref. & \\
\hline \multicolumn{6}{|l|}{ Membership in self-help groups ${ }^{c}$} \\
\hline Yes & $4(2.6)$ & $57(36.8)$ & $94(60.7)$ & 0.52 & $<0.001$ \\
\hline No & $19(23.5)$ & $38(46.9)$ & $24(29.7)$ & ref. & \\
\hline
\end{tabular}

and acceptable services in resource-constrained settings is a global mental health priority. ${ }^{5}$ The Pati programme demonstrates that service provision is feasible in such a setting with a cadre of local community health workers being frontline care providers. The programme was acceptable to service users as indicated by the high level of engagement over nearly 4 years of follow-up, the involvement and endorsement of the programme by the community and increasing referrals from community-based selfhelp groups in the later years of the programme (Fig 2). The programme facilitated the social participation of people with 


\begin{tabular}{|c|c|c|c|}
\hline & Coefficient ( $\beta$ ) & $P$ & $95 \% \mathrm{Cl}$ \\
\hline $\begin{array}{l}\text { Gender } \\
\text { Female } \\
\text { Male }\end{array}$ & $\begin{array}{l}0.03 \\
\text { ref. }\end{array}$ & 0.68 & -0.11 to 0.16 \\
\hline $\begin{array}{l}\text { Age, years } \\
\quad \leqslant 30 \\
31-40 \\
\geqslant 41\end{array}$ & $\begin{array}{l}-0.08 \\
-0.07 \\
\text { ref. }\end{array}$ & $\begin{array}{l}0.42 \\
0.32\end{array}$ & $\begin{array}{l}-0.27 \text { to } 0.11 \\
-0.26 \text { to } 0.11\end{array}$ \\
\hline IDEAS baseline disability score & -0.17 & 0.004 & -0.28 to -0.05 \\
\hline $\begin{array}{l}\text { Formal education } \\
\text { Non-literate } \\
\text { Literate }\end{array}$ & $\begin{array}{l}-0.23 \\
\text { ref. }\end{array}$ & 0.01 & -0.41 to -0.05 \\
\hline $\begin{array}{l}\text { Diagnosis } \\
\text { Schizophrenia } \\
\text { Bipolar affective disorder } \\
\text { Other psychosis }\end{array}$ & $\begin{array}{l}-0.51 \\
-0.21 \\
\text { ref. }\end{array}$ & $\begin{array}{c}<0.001 \\
0.03\end{array}$ & $\begin{array}{l}-0.69 \text { to }-0.33 \\
-0.41 \text { to }-0.02\end{array}$ \\
\hline $\begin{array}{l}\text { Family engagement } \\
\text { Present } \\
\text { Absent }\end{array}$ & $\begin{array}{l}0.21 \\
\text { ref. }\end{array}$ & 0.02 & 0.03 to 0.40 \\
\hline $\begin{array}{l}\text { Medication adherence } \\
\text { Yes } \\
\text { No }\end{array}$ & $\begin{array}{l}0.42 \\
\text { ref. }\end{array}$ & $<0.001$ & 0.21 to 0.63 \\
\hline $\begin{array}{l}\text { Status of follow-up } \\
\text { Dropped out } \\
\text { Continued follow-up and planned discharge }\end{array}$ & $\begin{array}{l}-0.30 \\
\text { ref. }\end{array}$ & 0.02 & -0.55 to -0.06 \\
\hline $\begin{array}{l}\text { Member of a self-help group } \\
\text { Yes } \\
\text { No }\end{array}$ & $\begin{array}{l}0.20 \\
\text { ref. }\end{array}$ & 0.01 & 0.05 to 0.36 \\
\hline
\end{tabular}

psychotic disorders and helped address their economic concerns through linkages with existing employment schemes and microcredit facilities. Social disadvantage (as indicated by lack of education) and inadequate family engagement with the programme predicted poorer functional outcomes, as reported from another long-term outcome study in India. ${ }^{14}$

Two components of the community-based package emerged as being independent predictors of favourable outcomes: adherence to psychotropic medication and participation in self-help groups. Medication adherence has recently been demonstrated to be effective in reducing disability in a community cohort of people with schizophrenia in rural India. ${ }^{15}$ A combination of methods, accessible and home-based services, psychoeducation, enlisting family and community support, were used to promote adherence and engagement with services. There are close conceptual similarities of the inclusive community-based rehabilitation services in this programme and the capability-oriented recovery approach. ${ }^{16}$

Our study adds to the limited evidence ${ }^{17}$ on the impact of community-oriented service delivery models for people with psychotic disorders in low- and middle-income countries in three respects. First, our results add to the evidence that the community-based rehabilitation approach is a feasible and acceptable model of service provision for people with psychotic disorders in a particularly challenging rural setting in India. Second, the study provides a template of the structure, content and process of service delivery that can be replicated. Finally, the results underline the benefits of health programmes engaging with local communities to maximise restoration of social roles of people with psychoses. In this case, access to microcredit facilities through self-help groups in Pati had mutual benefits for service users and the community. The self-help groups were the structural basis of community support and members of the group took an increasingly active role in making referrals to the programme, supported and gave practical assistance to families, and made preferential loans to people recovering from their illness to improve their livelihoods. Most importantly, these groups supported the social inclusion of people with psychosis in mainstream community activities and reduced discrimination. The community-based rehabilitation service was also reasonably successful in addressing some of the common barriers to equitable access in health programmes such as female gender, poverty and belonging to a disadvantaged social group.

\section{Policy and research implications}

Our study has a number of strengths that partially offset some of its limitations (see below). First, the study shows the importance and feasibility of monitoring routine process and outcome data in mental health services using existing human resources. Second, we have reported outcomes over a median of 4 years, the longest such period of follow-up of a health service programme from any low- and middle-income country. Third, the high rates of endpoint assessments ensure that the findings are not compromised by attrition bias. Fourth, unlike previous studies, which have focused on schizophrenia exclusively, this study describes the outcomes for people with a range of chronic psychotic disorders, which is more relevant for programme planning and implementation. Finally, in contrast to most existing studies, which define outcomes using clinical measures, we used broader outcome measures related to function, which were culturally valid and locally generated.

There are important policy and research implications of this programme for the planning of community services for people with severe mental disorders in low- and middle-income countries. The results provide evidence that community-based rehabilitation programmes relying primarily on non-specialist health workers are acceptable and feasible, and have an impact 
on the social and economic functioning of people with psychotic disorders and their families. The most important limitation of our study is that, by being derived from the monitoring and evaluation of an ongoing community mental health intervention rather than a controlled clinical trial evaluation, we are unable to comment on the effectiveness of the intervention. Furthermore, the findings are nested in the particular social and cultural milieu of the tribal community in Pati; the unique challenges and opportunities for the programme may not necessarily generalise to other settings easily. These limitations will be addressed through an ongoing controlled clinical trial of the interventions in two diverse settings in India, currently in progress. We propose that, based on the evidence accrued so far, community-based rehabilitation is a promising approach to closing the treatment gap for people with severe mental disorders in low- and middleincome countries.

Sudipto Chatterjee, MD, DPM, Sangath, Goa, India, and London School of Hygiene and Tropical Medicine, UK; Aravind Pillai, MBBS, MPH, Sangath, Goa, India, and Mailman School of Public Health, Columbia University, New York, USA; Sumeet Jain BA, BSW, MSW, Centre for Behavioural and Social Sciences in Medicine, Department of Medicine, University College London, UK; Alex Cohen, PhD, Department of Social Medicine, Harvard Medical School, Boston, Massachussetts, USA; Vikram Patel MRCPsych, PhD, Sangath, Goa, India, and London School of Hygiene and Tropical Medicine, UK

Correspondence Professor Vikram Patel, Sangath Centre, Porvorim, Goa, India 403521. Email: vikram.patel@Ishtm.ac.uk

First received 22 Jul 2008, final revision 25 May 2009, accepted 17 Jun 2009

\section{Funding}

This programme was partly supported by the Sir Dorabji Tata Trust, a registered charity in Mumbai, India. V.P. is supported by a Wellcome Trust Senior Clinical Research Fellowship in Tropical Medicine.

\section{Acknowledgements}

We thank the Pati programme staff, in particular, the then Programme Director, Dr Ashish Gupta, for their support in conducting the programme and in recording the data meticulously. We would also like to thank the management of Ashagram Trust for allowing us to conduct the study. Finally, we are deeply indebted to the participants, their families, the self-help group members and the communities where the programme was conducted for their support and generosity during the data collection process.

\section{References}

1 World Health Organization. The World Health Report 2001. Mental Health: New Understanding, New Hope. WHO, 2001.

2 Saxena S, Sharan P, Garrido M, Saraceno B. World Health Organization's Mental Health Atlas 2005: implications for policy development. World Psychiatry 2006; 5: 179-84.

3 Hyman S, Chisholm D, Kessler R, Patel V, Whiteford H. Mental disorders. In Disease Control Priorities in Developing Countries (2nd edn) (eds DT Jamison, JG Breman, AR Measham, G Alleyne, M Cleason, DB Evans, et al): 605-25. Oxford University Press, 2006.

4 Saraceno B, van Ommeren M, Batniji R, Cohen A, Gureje O, Majoney J, et al. Barriers to improvement of mental health services in low-income and middle-income countries. Lancet 2007; 370: 1164-74.

5 Lancet Global Mental Health Group. Scale up services for mental disorders: a call to action. Lancet 2007; 370: 1241-52.

6 Saxena S, Thornicroft G, Knapp M, Whiteford H. Resources for mental health: scarcity, inequity, and inefficiency. Lancet 2007; 370: 878-89.

7 Patel V, Farooq S, Thara R. What is the best approach to treating schizophrenia in developing countries? PLOS Med 2007; 4: e159.

8 International Labour Office, United Nations Educational, Scientific and Cultural Organization, World Health Organization. CBR. A Strategy for Rehabilitation, Equalization of Opportunities, Poverty Reduction and Social Inclusion of People with Disabilities. WHO, 2004.

9 Chatterjee S, Patel V, Chatterjee A, Weiss HA. Evaluation of a communitybased rehabilitation model for chronic schizophrenia in rural India. Br J Psychiatry 2003; 182: 57-62.

10 Patel V, Araya R, Chatterjee S, Chisholm D, Cohen A, De Silva M, et al. Treatment and prevention of mental disorders in low-income and middleincome countries. Lancet 2007; 370: 991-1005.

11 Rehabilitation Committee of Indian Psychiatric Society. IDEAS (Indian Disability Evaluation and Assessment Scale) - A Scale for Measuring and Quantifying Disability in Mental Disorders. Indian Psychiatric Society, 2002.

12 World health Organization. The ICD-10 Classification of Mental and Behavioural Disorders. WHO, 1992.

13 Lopez AD, Mathers CD, Ezzati M, Jamison DT, Murray CJL. Global Burden of Disease and Risk Factors. Oxford University Press, 2006.

14 Thara R. Twenty-year course of schizophrenia: the Madras Longitudinal Study. Can J Psychiatry 2004; 49: 564-9.

15 Thirthalli J, Venkatesh BK, Kishorekumar KV, Arunachala U, Venkatasubramanian G, Subbakrishna DK, et al. Prospective comparison of course of disability in antipsychotic-treated and untreated schizophrenia patients. Acta Psychiatr Scand 2009; 119: 209-17.

16 Hopper K. Rethinking social recovery in schizophrenia: what a capabilities approach might offer. Soc Sci Med 2007; 65: 868-79.

17 Wiley-Exley E. Evaluations of community mental health care in low- and middle-income countries: a 10-year review of the literature. Soc Sci Med 2007; 64: 1231-41. 